\title{
NEWS
}

\section{Is it ever better not to have health insurance?}

\author{
Cite as: CMAJ 2017 November 27;189:E1466. doi: 10.1503/cmaj.109-5528
}

Posted on cmajnews.com on Nov. 6, 2017.

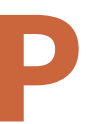

atients in United States hospitals can find themselves in a difficult situation if they learn they have diabetes, cancer or another ailment that will require ongoing medical care.

"It really helps to have health insurance, or a trust fund," Heidi Allen, who teaches health policy at Columbia University, said during her presentation at TEDMED 2017. "What do you do if you don't have health insurance or money? The answer to that question depends on where you live and what your state policy-makers think they know about Medicaid."

Medicaid is the US health insurance system for low-income Americans. About 75 million people are enrolled, including 12 million who gained access because of the Affordable Care Act (ACA). The program was expanded in 31 states thanks to ACA funding, but 19 states still haven't decided if they should follow suit.

"When it comes to the future of the Medicaid program, it seems we can't agree on goals," said Allen. "We definitely don't agree on policies. The really troubling thing is that we can't even agree on facts."

Some policy-makers claim that being on Medicaid is worse than having no health insurance at all. This is mainly due to persistent myths about the program, said Allen. One of those myths is that Medicaid pays so little that doctors won't see patients on the program, making the insurance essentially worthless.

"If no doctor will see you, then it amounts to what we call coverage without care," said Allen. "What is the point of having a Medicaid card if you don't have access to a doctor?"

Another myth, according to Allen, is that even if you do get access to a doctor, the quality of care is so poor that it may actually cause harm. If that were true, it

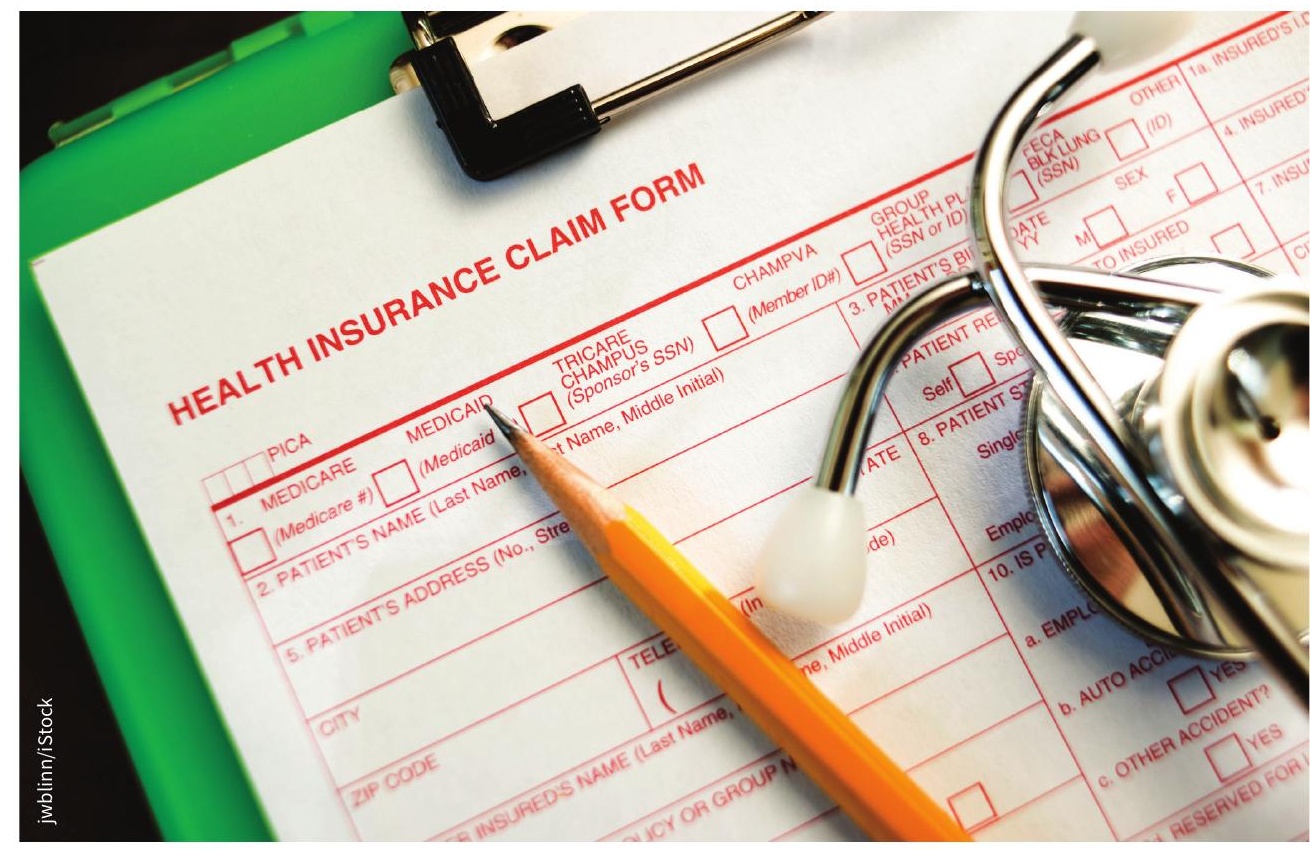

Some US politicians claim having Medicaid is worse than being uninsured. But what does the evidence say?

would be better to be uninsured, some politicians have argued.

"No wonder so many states have resisted expanding Medicaid," said Allen.

To help debunk the myths, Allen participated in what became known as the Oregon Health Insurance Experiment. In 2008, Oregon had enough money to extend Medicaid to 10000 people. It held a lottery to determine who would receive coverage, and 90000 people applied. Researchers followed both the winners and losers of the lottery for two years and measured health outcomes.

"What was clear is that our Medicaid recipients reported improvements in health because of Medicaid, and we saw no evidence to the contrary," said Allen. "Medicaid is not dangerous."

The lottery participants who received insurance reported much better access to physicians than those that didn't receive
Medicaid. They were more likely to have filled a prescription for medication in the previous year, and reported that the care they received was of high quality. Researchers also found insurance coverage to be associated with an increase in detection and treatment of diabetes and depression.

"Medicaid isn't perfect, but being uninsured is really tough. Being uninsured is scary if you are healthy and downright terrifying if you are not," said Allen. "It's time to set aside our myths and have a thoughtful national dialog about the Medicaid program."

\section{Roger Collier, CMAJ}

Editor's note: The Canadian Medical Association (CMA) is a global partner of TEDMED, but as with all CMAJ articles, the CMA and its subsidiaries, including Joule, owner of CMAJ, were not involved in the editorial decision-making process for this article. 